(C) 1984. The Genetical Society of Great Britain

\title{
METHODS OF ANALYSIS AND THE ESTIMATION OF THE GENETIC PARAMETERS FROM A DIALLEL SET OF CROSSES
}

\author{
H. S. POONI, J. L. JINKS AND R. K. SINGH* \\ Department of Genetics, University of Birmingham, Birmingham B15 2TT, England
}

Received 28.vii.83

\begin{abstract}
SUMMARY
The relationships between the estimates of general $\left(\sigma_{g}^{2}\right)$ and specific $\left(\sigma_{s}^{2}\right)$ combining abilities obtained from the four methods of diallel analysis described by Griffing (1956) and estimates of $D_{R}$ and $H_{R}$, the additive and dominance components of variability, are compared both theoretically and experimentally for model II situations. Theoretically they are compared by deriving the expectations of the variance components for the general and specific combining abilities for each method in terms of the genetical parameters $\sum u_{i} v_{i} d_{i}^{2}, \sum u_{i} v_{i} h_{i}^{2}, \sum u_{i}^{2} v_{i}^{2} h_{i}^{2}$ and $\sum u_{i} v_{i}\left(u_{i}-v_{i}\right) d_{i} h_{i}$. Experimentally they are compared by extracting data from a diallel set of crosses between a random sample of $29 F_{9}$ families derived from the $F_{2}$ of the cross of varieties 1 and 5 of Nicottana rustica by pedigree inbreeding.

The theoretical results show and the experimental results confirm that the genetical expectations of $\sigma_{\mathrm{g}}^{2}$ and $\sigma_{s}^{2}$ for method 1 are identical with the general definitions of $\frac{1}{4} D_{R}$ and $\frac{1}{2} H_{R}$. This method, therefore, gives consistent estimates of $D_{R}$ and $H_{R}$ in all situations. In contrast, methods 2,3 and 4 give close approximations to $\frac{1}{4} D_{R}$ and $\frac{1}{4} H_{R}$ only when estimates from diallels involve large numbers of parents.

The limitations of diallel analysis as a source of estimates of genetically defined as opposed to statistically defined parameters are discussed.
\end{abstract}

\section{INTRODUCTION}

Griffing (1956) has described methods for analysing (a) full diallel with selfs; (b) half diallel with selfs; (c) full diallel without selfs and (d) half diallel without selfs: and estimating the components of variance for general $\left(\sigma_{g}^{2}\right)$ and specific $\left(\sigma_{s}^{2}\right)$ combining abilities. However, little has been published either about the genetical expectations of these components $\left(\sigma_{g}^{2}\right.$ and $\left.\sigma_{s}^{2}\right)$ or how their estimates relate to the values of $\frac{1}{4} D_{R}$ and $\frac{1}{4} H_{R}$, which are the additive and dominance components of a randomly mating population. With this objective we shall compare the genetical expectations of the $\sigma_{g}^{2}$ and $\sigma_{s}^{2}$ components obtained from all four methods for model II situations using genetical parameters defined by Hayman (1954), Jinks (1954) and Mather and Jinks (1982) and illustrate the theory by analysing a $20 \times 20$ diallel produced by Breese (1955) from a random sample of inbred lines which were extracted from the $\mathrm{F}_{2}$ of the cross of varieties 1 and 5 of Nicotiana rustica.

\section{THEORY}

We shall compare the four methods of Griffing (1956), which we shall refer to as 1 to 4 , by obtaining the theoretical expectations of their $\sigma_{g}^{2}$ and

* Permanent address: Department of Genetics, College of Basic Sciences, Haryana Agricultural University, Hissar, India. 
$\sigma_{s}^{2}$ components in terms of $\sum u_{i} v_{i} d_{i}^{2}, \sum u_{i} v_{i} h_{i}^{2}, \sum u_{i}^{2} v_{i}^{2} h_{i}^{2}, \sum u_{i} v_{i}\left(u_{i}-v_{i}\right) d_{i} h_{i}$ and $\sum u_{i}^{2} v_{i}^{2} h_{i}^{2}$, respectively, (see Jinks, 1954 and Mather and Jinks, 1982, for definitions). Following Griffing we shall use $U_{i}$ and $V_{i}$ as the actual numbers of inbred parents in which the alternative alleles are fixed with respect to the $i$ th locus with a further proviso that $U_{i} / u_{i}=V_{i} / v_{i}=p$, the number of parents in a diallel crossing programme. However, to make the expectations valid for a population we shall assume $p$ to be large and finite. We shall also assume that epistasis, genotype environmental interaction, linkage, multiple allelism, reciprocal differences, differential gametic selection etc. are absent.

We obtain the estimates of $\sigma_{g}^{2}$ and $\sigma_{s}^{2}$ as the variances of individual gca and sca effects which in turn are estimated from the formulae given by Griffing (1956). To illustrate the method used to obtain these variances we shall present the derivation procedure for method 1 .

For any locus $i$ for which alternative alleles $(A$ and $a$ ) are fixed amongst the sample of inbred lines, the diallel set of crosses produced from them have the following expectations:

\begin{tabular}{|c|c|c|c|c|}
\hline \& parent & $\delta$ parent & $\begin{array}{l}A A \\
\left(U_{a}\right)\end{array}$ & $\begin{array}{c}a a \\
\left(V_{a}\right)\end{array}$ & Row total \\
\hline $\begin{array}{l}A A \\
\left(U_{a}\right)\end{array}$ & $\begin{array}{l}\text { Frequency } \\
\text { Genotype } \\
\text { Score }\end{array}$ & $\begin{array}{c}U_{a}^{2} \\
A A \\
m+d_{a}\end{array}$ & $\begin{array}{c}U_{a} V_{a} \\
A a \\
m+h_{a}\end{array}$ & $p m+U_{a} d_{a}+V_{a} h_{a}$ \\
\hline $\begin{array}{l}a a \\
\left(V_{a}\right)\end{array}$ & $\begin{array}{l}\text { Frequency } \\
\text { Genotype } \\
\text { Score }\end{array}$ & $\begin{array}{c}U_{a} V_{a} \\
A a \\
m+h_{a}\end{array}$ & $\begin{array}{c}V_{a}^{2} \\
a a \\
m-d_{a}\end{array}$ & $p m-V_{a} d_{a}+U_{a} h_{a}$ \\
\hline
\end{tabular}

Column total $\quad p m+U_{a} d_{a}+V_{a} h_{a} \quad p m-V_{a} d_{a}+U_{a} h_{a} \quad p^{2} m+p\left(U_{a}-V_{a}\right) d_{a}+2 U_{a} V_{a} h_{a}$

Here $U_{a}$ and $V_{a}$ are the actual numbers of inbreds with $A A$ and $a a$ genotypes respectively, whereas $m, d_{a}$ and $h_{a}$ are the mean, additive genetic and dominance effects as defined by Mather and Jinks (1982). Using Griffing's formulae we obtain

$$
\begin{aligned}
\operatorname{gca}(A A) & =\frac{1}{2 p}\left\{2 p m+U_{a} d_{a}+V_{a} h_{a}\right\}-\frac{1}{p^{2}}\left\{p^{2} m+p\left(U_{a}-V_{a}\right) d_{a}+2 U_{a} V_{a} h_{a}\right\} \\
& =\frac{V_{a} d_{a}}{p}-\frac{V_{a}\left(U_{a}-V_{a}\right) h_{a}}{p^{2}}
\end{aligned}
$$

and

$$
\begin{aligned}
\operatorname{gca}(a a) & =\frac{1}{2 p}\left\{2 p m-V_{a} d_{a}+U_{a} h_{a}\right\}-\frac{1}{p^{2}}\left\{p^{2} m+p\left(U_{a}-V_{a}\right) d_{a}+2 U_{a} V_{a} h_{a}\right\} \\
& =-\frac{U_{a} d_{a}}{p}+\frac{U_{a}\left(U_{a}-V_{a}\right) h_{a}}{p^{2}}
\end{aligned}
$$

and their respective frequencies are $U_{a}$ and $V_{a}$. The variance of these values 
is obtained as $\left\{U_{a} g c a(A A)^{2}+V_{a} g c a(a a)^{2}\right\} / p$ which is equal to

$$
\frac{U_{a} V_{a} d_{a}^{2}}{p^{2}}+\frac{U_{a} V_{a} h_{a}^{2}}{p^{2}}-\frac{4 U_{a}^{2} V_{a}^{2} h_{a}^{2}}{p^{4}}-\frac{2 U_{a} V_{a}\left(U_{a}-V_{a}\right) d_{a} h_{a}}{p^{3}}
$$

Similarly we obtain the sca values for $A A, A a$ and $a a$ as

$$
-\frac{2 V_{a}^{2} h_{a}}{p^{2}}, \quad \frac{2 U_{a} V_{a} h_{a}}{p^{2}} \text { and }-\frac{2 U_{a}^{2} h_{a}}{p^{2}}
$$

respectively and their variance as $\frac{1}{2}\left\{U_{a}^{2}\left(-2 V_{a}^{2} h_{a}\right)^{2}+2 U_{a} V_{a}\left(2 U_{a} V_{a} h_{a}\right)^{2}+\right.$ $V_{a}^{2}\left(-2 U_{a}^{2} h_{a}\right)^{2} / p^{6}$ which is equal to $\left(4 U_{a}^{2} V_{a}^{2} h_{a}^{2}\right) / p^{4}$.

For many loci these expectations become

$$
\sigma_{g}^{2}=\frac{\sum U_{i} V_{i} d_{i}^{2}}{p^{2}}+\frac{\sum U_{i} V_{i} h_{i}^{2}}{p^{2}}-\frac{4 \sum U_{i}^{2} V_{i}^{2} h_{i}^{2}}{p^{4}}-\frac{2 \sum U_{i} V_{i}\left(U_{i}-V_{i}\right) d_{i} h_{i}}{p^{3}}
$$

and

$$
\sigma_{s}^{2}=\frac{4 \sum U_{i}^{2} V_{i}^{2} h_{i}^{2}}{p^{4}}
$$

which are the sums over all loci.

These expectations together with those for methods 2,3 and 4 are listed in table 1 . The contributions of the various components to $\sigma_{g}^{2}$ and $\sigma_{s}^{2}$ obviously differ between methods. For example, the cross product $d_{i} h_{i}$ has a coefficient of $2 \sum U_{i} V_{i}\left(U_{i}-V_{i}\right) / p^{3}$ for the full diallel (method 1); $2 \sum U_{i} V_{i}\left(U_{i}-V_{i}\right) / p^{2}(p+2)$ for half diallel with selfs (method 2); $2 \sum U_{i} V_{i}\left(U_{i}-V_{i}\right) / p^{2}(p-2)$ for full diallel without selfs (method 3) and $2 \sum U_{i} V_{i}\left(U_{i}-V_{i}\right) / p^{2}(p-2)$ for half diallel without selfs (method 4). These differences and those for the other components of $\sigma_{g}^{2}$, however, depend only on the number of parents in the diallel. In contrast, coefficients of $h_{i}^{2}$ for $\sigma_{s}^{2}$ are affected in a more complicated manner.

To quantify these effects for $\sigma_{\mathrm{g}}^{2}$ the coefficients for $\sum u_{i} v_{i} d_{i}^{2}, \sum u_{i} v_{i} h_{i}^{2}$, $4 \sum u_{i}^{2} v_{i}^{2} h_{i}^{2}$ and $2 \sum u_{i} v_{i}\left(u_{i}-v_{i}\right) d_{i} h_{i}$ have been obtained by substituting $p$ equals $4,8,10,20$ and 100 into the formulae to cover a whole range of possible diallel crossing programmes after substituting $U_{i}=u_{i} p$ and $V_{i}=$ $v_{i} p$ to standardise the parameters. The values of these coefficients are given in table 2. For the smaller values of $p$ it is unlikely in practice that the gene frequencies in the sample of parents would be the same as in the parental population, we have, however, assumed them to be the same.

For $\sigma_{s}^{2}$ the same range of values have been substituted for $p$ and in addition gene frequencies have been varied between $u=v=\frac{1}{2}$ and $u=\frac{3}{4}$ and $v=\frac{1}{4}$. These gene frequencies have, however, been assumed to apply to all loci for which the parental population varies. The coefficients, standardised in each case to apply to $4 \sum u_{i}^{2} v_{i}^{2} h_{i}^{2}$ so that the actual values of $\sigma_{s}^{2}$ can be compared between methods, are given in table 3 .

\section{Materials}

(i) The experiment

During 1943 a cross between two inbred varieties V1 and V5 of Nicotiana rustica was initiated by Mather and Vines at Merton, South 
TABLE 1

Theoretical expectations of $\sigma_{\mathrm{g}}^{2}$ and $\sigma_{s}^{2}$ for methods 1 to 4 of diallel analysis proposed by Griffing (1956)

\begin{tabular}{ll}
\hline Method & Expectation \\
\hline
\end{tabular}

(a) General combining ability $\sigma_{g}^{2}$

1. Full diallel with selfs

$\frac{\sum U_{i} V_{i} d_{i}^{2}}{p^{2}}+\frac{\sum U_{i} V_{i} h_{i}^{2}}{p^{2}}-\frac{4 \sum U_{i}^{2} V_{i}^{2} h_{i}^{2}}{p^{4}}-\frac{2 \sum U_{i} V_{i}\left(U_{i}-V_{i}\right) d_{i} h_{i}}{p^{3}}$

2. Half diallel with selfs

$\frac{\sum U_{i} V_{i} d_{i}^{2}}{p^{2}}+\frac{\sum U_{i} V_{i} h_{i}^{2}}{(p+2)^{2}}-\frac{4 \sum U_{i}^{2} V_{i}^{2} h_{i}^{2}}{p^{2}(p+2)^{2}}-\frac{2 \sum U_{i} V_{i}\left(U_{i}-V_{i}\right) d_{i} h_{i}}{p^{2}(p+2)}$

3. Full diallel without selfs

$\frac{\sum U_{i} V_{i} d_{i}^{2}}{p^{2}}+\frac{\sum U_{i} V_{i} h_{i}^{2}}{(p-2)^{2}}-\frac{4 \sum U_{i}^{2} V_{i}^{2} h_{i}^{2}}{p^{2}(p-2)^{2}}-\frac{2 \sum U_{i} V_{i}\left(U_{i}-V_{i}\right) d_{i} h_{i}}{p^{2}(p-2)}$

4. Half diallel without selfs

$\frac{\sum U_{i} V_{i} d_{i}^{2}}{p^{2}}+\frac{\sum U_{i} V_{i} h_{i}^{2}}{(p-2)^{2}}-\frac{4 \sum U_{i}^{2} V_{i}^{2} h_{i}^{2}}{p^{2}(p-2)^{2}}-\frac{2 \sum U_{i} V_{i}\left(U_{i}-V_{i}\right) d_{i} h_{i}}{p^{2}(p-2)}$

(b) Specific combining ability $\sigma_{s}^{2}$

1. Full diallel with selfs

$$
\frac{4 \sum U_{i}^{2} V_{i}^{2} h_{i}^{2}}{p^{4}}
$$

2. Half diallel with selfs

$$
\begin{aligned}
& \frac{4 \sum U_{i}\left(U_{i}+1\right) V_{i}\left(V_{i}+1\right) h_{i}^{2}}{p(p+1)^{2}(p+2)} \\
& \frac{4 \sum U_{i}\left(U_{i}-1\right) V_{i}\left(V_{i}-1\right) h_{i}^{2}}{p(p-1)^{2}(p-2)} \\
& \frac{4 \sum U_{i}\left(U_{i}-1\right) V_{i}\left(V_{i}-1\right) h_{i}^{2}}{p(p-1)^{2}(p-2)}
\end{aligned}
$$

* $U_{i}$ and $V_{i}$ are the actual numbers of inbreds which have alternative alleles fixed in them for the $i$ th locus.

\begin{tabular}{|c|c|c|c|c|}
\hline $\begin{array}{l}\text { No. of parents } \\
\text { in a diallel }\end{array}$ & $\sum u_{i} v_{i} h_{i}^{2}$ & $\sum u_{i} v_{i} h_{i}^{2}$ & $\begin{array}{l}\text { nts of } \\
4 \sum u_{i}^{2} v_{i}^{2} h_{i}^{2}\end{array}$ & $2 \sum u_{i} v_{i}\left(u_{i}-v_{i}\right) d_{i} h_{i}$ \\
\hline \multicolumn{5}{|c|}{ Method 1: Full diallel with selfs } \\
\hline Any & $1 \cdot 0000$ & $1 \cdot 0000$ & $1 \cdot 0000$ & $1 \cdot 0000$ \\
\hline \multicolumn{5}{|c|}{ Method 2: Half diallel with selfs } \\
\hline 4 & $1 \cdot 0000$ & 0.4444 & 0.4444 & 0.6666 \\
\hline 8 & $1 \cdot 0000$ & 0.6400 & 0.6400 & 0.8000 \\
\hline 10 & $1 \cdot 0000$ & 0.6944 & 0.6944 & 0.8333 \\
\hline 20 & $1 \cdot 0000$ & 0.8264 & 0.8264 & 0.9090 \\
\hline 100 & $1 \cdot 0000$ & 0.9612 & 0.9612 & 0.9804 \\
\hline$\infty$ & $1 \cdot 0000$ & $1 \cdot 0000$ & $1 \cdot 0000$ & $1 \cdot 0000$ \\
\hline \multicolumn{5}{|c|}{ Methods 3 and 4: Full and half diallel without selfs } \\
\hline 4 & $1 \cdot 0000$ & $4 \cdot 0000$ & $4 \cdot 0000$ & $2 \cdot 0000$ \\
\hline 8 & $1 \cdot 0000$ & $1 \cdot 7777$ & $1 \cdot 7777$ & $1 \cdot 3333$ \\
\hline 10 & $1 \cdot 0000$ & $1 \cdot 5625$ & 1.5625 & $1 \cdot 2500$ \\
\hline 20 & $1 \cdot 0000$ & $1 \cdot 2346$ & $1 \cdot 2346$ & $1 \cdot 1111$ \\
\hline 100 & $1 \cdot 0000$ & $1 \cdot 0412$ & $1 \cdot 0412$ & $1 \cdot 0204$ \\
\hline$\infty$ & $1 \cdot 0000$ & $1 \cdot 0000$ & 1.0000 & $1 \cdot 0000$ \\
\hline
\end{tabular}

\section{TABLE 2}

Expected coefficients of $\sum u_{i} v_{i} d_{i}^{2}, \sum u_{i} v_{i} h_{i}^{2}, 4 \sum u_{i}^{2} v_{i}^{2} h_{i}^{2}$ and $2 \sum u_{i} v_{i}\left(u_{i}-v_{i}\right) d_{i} h_{i}$ for various sizes of diallel crosses 
TABLE 3

Expected coefficients of $4 \sum u_{i}^{2} v_{i}^{2} h_{i}^{2}$ for various sizes of diallel when $u$ and $v$ take values of $\frac{3}{4}$ and $\frac{1}{4}$, and $\frac{1}{2}$ and $\frac{1}{2}$, respectively

\begin{tabular}{|c|c|c|c|c|c|c|c|}
\hline \multirow[b]{2}{*}{ Method } & \multicolumn{7}{|c|}{ Number of parents in the diallel } \\
\hline & $u: v$ & 4 & 8 & 10 & 20 & 100 & $\infty$ \\
\hline 1. Full diallel & $\frac{3}{4}: \frac{1}{4}$ & $1 \cdot 0$ & $1 \cdot 0$ & $1 \cdot 0$ & $1 \cdot 0$ & 1.0 & $1 \cdot 0$ \\
\hline with selfs & $\frac{1}{2}: \frac{1}{2}$ & $1 \cdot 0$ & $1 \cdot 0$ & $1 \cdot 0$ & $1 \cdot 0$ & $1 \cdot 0$ & \\
\hline $\begin{array}{l}\text { 2. Half diallel } \\
\text { with selfs }\end{array}$ & $\begin{array}{l}\frac{3}{4}: \frac{1}{4} \\
\frac{1}{2}: \frac{1}{2}\end{array}$ & $\begin{array}{l}1 \cdot 1380 \\
0.96\end{array}$ & $\begin{array}{l}1 \cdot 1067 \\
0.9876\end{array}$ & $\begin{array}{l}1.0932 \\
0.9916\end{array}$ & $\begin{array}{l}1.0555 \\
0.9976\end{array}$ & $\begin{array}{l}1.0135 \\
1.0000\end{array}$ & $\begin{array}{l}1.0 \\
1.0\end{array}$ \\
\hline $\begin{array}{l}\text { 3. Full diallel } \\
\text { without selfs }\end{array}$ & $\begin{array}{l}\frac{3}{4}: \frac{1}{4} \\
\frac{1}{2}: \frac{1}{2}\end{array}$ & $\begin{array}{l}0 \cdot 0 \\
0 \cdot 8888\end{array}$ & $\begin{array}{l}0.7257 \\
0.9796\end{array}$ & $\begin{array}{l}0.8026 \\
0.9876\end{array}$ & $\begin{array}{l}0.9194 \\
0.9972\end{array}$ & $\begin{array}{l}0.9863 \\
0.9999\end{array}$ & $\begin{array}{l}1 \cdot 0 \\
1 \cdot 0\end{array}$ \\
\hline $\begin{array}{l}\text { 4. Half diallel } \\
\text { without selfs }\end{array}$ & $\begin{array}{l}\frac{3}{4}: \frac{1}{4} \\
\frac{1}{2}: \frac{1}{2}\end{array}$ & $\begin{array}{l}0.0 \\
0.8888\end{array}$ & $\begin{array}{l}0.7257 \\
0.9796\end{array}$ & $\begin{array}{l}0.8026 \\
0.9876\end{array}$ & $\begin{array}{l}0.9194 \\
0.9972\end{array}$ & $\begin{array}{l}0.9863 \\
0.9999\end{array}$ & $\begin{array}{l}1 \cdot 0 \\
1 \cdot 0\end{array}$ \\
\hline
\end{tabular}

London (Mather and Vines, 1952). Subsequently a controlled programme of pedigree inbreeding was carried out to produce a random sample of the inbred lines which can be extracted from the cross. In 1954 twenty $F_{9}$ lines, each produced from a separate $F_{2}$ plant, were diallely crossed to produce 20 selfs and 190 pairs of reciprocal $F_{1}$ 's. These families were raised during the summer of 1955 in a randomised layout in two blocks where each family was allocated a single row plot of 5 plants at random. Adequate guards were provided to avoid differential competition between the experimental plants and each plant was scored for flowering time in days from an arbitrary date and for final height in inches at the end of the season.

\section{AnAlyses}

Before we submit the data to the combining ability analyses we shall test for some important assumptions made in section 2 . These tests we can carry out by applying the analysis of variance of Hayman (1954a) and the $W_{r} / V_{r}$ graphic analysis and component estimation of Jinks (1954) and Hayman $(1954 b)$. These analyses have already been carried out by Jinks, Perkins and Breese (1969) and published with the analyses on test crosses. The results they obtained for final height point to the absence of gene interaction and linkage disequilibrium and provide a strong hint of allelic inequality with recessive alleles being more frequent than dominants. For flowering time there is, however, some evidence for epistasis or a linkage disequilibrium or both and gene frequencies are more likely to be equal than different. Jinks et al., (1969) also estimated various parameters which we summarise thus:

$$
4 \sum u_{i} v_{i} d_{i}^{2} \quad 4 \sum u_{i} v_{i} h_{i}^{2} \quad 16 \sum u_{i}^{2} v_{i}^{2} h_{i}^{2} \quad 8 \sum u_{i} v_{i}\left(u_{i}-v_{i}\right) d_{i} h_{i}
$$

Flowering

$\begin{array}{lllll}\text { time } & 14.20 & 1.91 & 1.29 & 6.07\end{array}$

Final

$\begin{array}{lllll}\text { height } & 36.49 & 3.60 & 0.28 & 12.20\end{array}$

The most appropriate combining ability analysis for our data is Griffing's Method 1 because it utilises information derived from every one of the 
TABLE 4

Mean squares of the analyses of variance of a $20 \times 20$ and four $5 \times 5$ diallels of Nicotiana rustica for methods 1 to 4 proposed by Griffing (1956)

\begin{tabular}{|c|c|c|c|c|c|c|}
\hline Item & df & $\begin{array}{c}20 \times 20 \text { diallel } \\
\text { Flowering } \\
\text { time }\end{array}$ & $\begin{array}{c}\text { Final } \\
\text { height }\end{array}$ & df & $\begin{array}{c}5 \times 5 \text { diallel } \\
\text { Flowering } \\
\text { time }\end{array}$ & $\begin{array}{l}\text { Final } \\
\text { height }\end{array}$ \\
\hline \multicolumn{7}{|c|}{ Method 1: Full diallel with selfs } \\
\hline GCA & 19 & $86.98^{* * *}$ & $268 \cdot 41^{* * *}$ & 16 & $27 \cdot 24^{* * *}$ & $77 \cdot 98^{* * *}$ \\
\hline SCA & 190 & $2 \cdot 39^{* * *}$ & $6 \cdot 46^{* * *}$ & 40 & $2 \cdot 28^{* * *}$ & $9 \cdot 36^{* * *}$ \\
\hline Recip. diffs & 190 & $2 \cdot 00^{* *}$ & $5 \cdot 49^{* *}$ & 40 & $2 \cdot 32^{* * *}$ & $5 \cdot 94^{* * *}$ \\
\hline Error & 384 & 0.99 & $3 \cdot 71$ & 92 & $0 \cdot 78$ & $3 \cdot 27$ \\
\hline \multicolumn{7}{|c|}{ Method 2: Half diallel with selfs } \\
\hline GCA & 38 & $51 \cdot 41^{* * *}$ & $150 \cdot 30^{* * *}$ & 32 & $21 \cdot 85^{* * *}$ & $56 \cdot 07^{* * *}$ \\
\hline SCA & 380 & $2 \cdot 23^{* * *}$ & $6 \cdot 46^{* *}$ & 80 & $2 \cdot 50^{* * *}$ & $8 \cdot 59$ \\
\hline Error & 384 & 0.99 & 3.71 & 92 & 0.78 & $3 \cdot 27$ \\
\hline \multicolumn{7}{|c|}{ Method 3: Full diallel without selfs } \\
\hline GCA & 19 & $73 \cdot 50^{* * * *}$ & $241 \cdot 09^{* * *}$ & 16 & $12 \cdot 85^{* * *}$ & $52 \cdot 22^{* * *}$ \\
\hline SCA & 170 & $2 \cdot 31^{* * *}$ & $5 \cdot 57^{* * *}$ & 20 & $1 \cdot 36^{*}$ & $5 \cdot 55^{* * *}$ \\
\hline Recip. diffs & 190 & $2 \cdot 00^{* * *}$ & $5 \cdot 49^{* * *}$ & 40 & $2 \cdot 32^{* * * *}$ & $5 \cdot 94^{* * *}$ \\
\hline Error & 384 & 0.99 & $3 \cdot 71$ & 92 & $0 \cdot 78$ & $3 \cdot 27$ \\
\hline \multicolumn{7}{|c|}{ Method 4: Half diallel without selfs } \\
\hline GCA & 38 & $37 \cdot 99^{* * * *}$ & $122 \cdot 17^{* * *}$ & 32 & 6.96 & $29 \cdot 07^{* * *}$ \\
\hline SCA & 340 & $2 \cdot 13^{* * *}$ & $5 \cdot 67^{* *}$ & 40 & $2 \cdot 24^{* * *}$ & $5 \cdot 58^{* * *}$ \\
\hline Error & 384 & 0.99 & $3 \cdot 71$ & 92 & $0 \cdot 78$ & $3 \cdot 27$ \\
\hline
\end{tabular}

${ }^{* * *} p<0.001 ;{ }^{* *} 0.01 \geqslant p \geqslant 0.001 ; * 0.05 \geqslant p>0.01 ; \mathrm{NS} p>0.05$.

families raised in the experiment. Method 3 can, however, be applied simply by excluding the selfs on the leading diagonal of the diallel table. This exclusion also allows the two halves of the diallel to be analysed as two independent experiments using method 4. By reinstating the selfs with either of these halves two separate sets of data are produced which can be analysed by method 2 .

The results of these analyses for each character using plot means are summarised in table 4. For methods 1 and 3 the mean squares for $g c a, s c a$ and reciprocal effects are tabulated for 19, 190 and 190 degrees of freedom respectively. For methods 2 and 4 the sum of squares from the two sets are pooled and the combined mean squares for $g c a$ and $s c a$ are presented for 38 and 380 degrees of freedom. In each case there is a common error variance obtained from the blocks $\times$ families interactions as $\frac{1}{5} \times m s_{(b \times f)}$ and the significance of various mean squares is tested according to Model II.

It is clear from tables 1,2 and 3 that the magnitudes of $\sigma_{g}^{2}$ and $\sigma_{s}^{2}$ can vary with $p$, the number of parents in the diallel. To see if it is true in practice our $20 \times 20$ diallel has been arbitrarily split into four $5 \times 5$ diallels and the analyses repeated for each diallel separately. To summarise these four analyses the relevant $s s$ 's and degrees of freedom over the diallels have been pooled to obtain cumulative mean squares. These are presented in table 4 for comparison. Again the tests of significance have been carried out according to Model II using $\frac{1}{5} \times m s_{(b \times f)}$ for 92 degrees of freedom as error variance.

Each item in table 4 is highly significant except the sca mean square for flowering time in the $5 \times 5$ diallels which is significant only at the 5 per 
TABLE 5

Estimates of $\sigma_{g}^{2}$ and $\sigma_{s}^{2}$ for $20 \times 20$ and $5 \times 5$ diallels as obtained from Methods 1 to 4 analyses

\begin{tabular}{lllll}
\hline Method & $\sigma_{B}^{2}$ & & & $\sigma_{s}^{2}$ \\
& & $p=20$ & $p=5$ & $p=20$ \\
\hline
\end{tabular}

(a) Flowering time

1. Full diallel with selfs

2. Half diallel with selfs

3. Full diallel without selfs

4. Half diallel without selfs

1. Full diallel with selfs

2. Half diallel with selfs

3. Full diallel without selfs

4. Half diallel without selfs

$\begin{array}{lccc}2.5031 & 2.1149 & 0.8928 & 0.7349 \\ 2.7645 & 2.2350 & 1.7231 & 1.2388 \\ & & (0.9531) & (0.7328)^{*} \\ 1.9169 & 1.9773 & 0.2915 & 0.6610 \\ 1.5754 & 1.9923 & 1.4631 & 1.1416 \\ & & (0.6931) & (0.6366)\end{array}$

(b) Final height

$\begin{array}{cccc}6.8910 & 6.5500 & 3.6250 & 1.4450 \\ 6.7823 & 6.5388 & 5.3183 & 2.7488 \\ & & (3.9841) & (1.8588) \\ 7.7779 & 6.5421 & 1.1391 & 0.9299 \\ 7.8319 & 6.4720 & 2.3083 & 1.9612 \\ & & (0.9741) & (1.0712)\end{array}$

\footnotetext{
* Values in brackets are obtained by subtracting the $\sigma_{\text {recips }}^{2}$ (from table 4) from the values given.
}

cent level. In every case the relevant component of variance $\left(\sigma_{g}^{2}\right.$ or $\left.\sigma_{s}^{2}\right)$ is, therefore, significantly greater than zero. The estimates of $\sigma_{g}^{2}$ and $\sigma_{s}^{2}$ obtained for these comparisons are given in table 5.

\section{RESUlts}

A number of patterns emerge from the theoretical expectations (tables 1,2 and 3) which are relevant to our practical results. Firstly, estimates of $\sigma_{g}^{2}$ are expected to differ between different methods only when the number of parents in the diallel is small $(p<10)$. They should, therefore, have the same value when obtained by any of the methods from diallel crosses involving a large number of parents (say $P>20$ ). Secondly, even when $p$ is small the differences between the estimates of $\sigma_{g}^{2}$ are expected to occur mainly (a) between those obtained from methods 1 and 2 and (b) between these estimates and those from methods 3 and 4 , the latter pair of estimates are themselves not expected to differ.

Method 1 should provide consistent estimates of $\sigma_{g}^{2}$ even when $p$, the number of parents, is reduced. This is because of a consistency of the coefficients of the genetical components of $\sigma_{g}^{2}$ which is independent of $p$. This, however, is not true for the other methods because the coefficients of $\sum u_{i} v_{i} h_{i}^{2}, 4 \sum u_{i}^{2} v_{i}^{2} h_{i}^{2}$ and $2 \sum u_{i} v_{i}\left(u_{i}-v_{i}\right) d_{i} h_{i}$ either decrease as in the case of method 2 or they increase as for methods 3 and 4 when $p$ is reduced. The contributions of $\sum u_{i} v_{i} d_{i}^{2}$ to the estimates of $\sigma_{g}^{2}$ in the four methods, on the other hand, remain the same as those for method 1 and are consistent over all methods. Consequently we expect either

or

$$
\sigma_{g}^{2}(\operatorname{method} 2)>\sigma_{g}^{2}(\operatorname{method} 1) \gg \sigma_{g}^{2}(\operatorname{method} 3) \simeq \sigma_{g}^{2}(\operatorname{method} 4)
$$

$$
\sigma_{g}^{2}(\operatorname{method} 2)<\sigma_{g}^{2}(\operatorname{method} 1) \ll \sigma_{g}^{2}(\operatorname{method} 3) \simeq \sigma_{g}^{2}(\operatorname{method} 4)
$$


to be true when both additive and dominance effects are significant and $p$ is small $(p<10)$. The four estimates, however, should gradually become equal to each other either as $p$ becomes very large $(p>100)$ or as the dominance becomes very small.

The coefficient of $\sigma_{s}^{2}$ when estimated by method 1 is again independent of change in $p$. For the remaining methods estimates of $\sigma_{s}^{2}$ seem to be equally affected by unequal gene frequencies and the size of the diallel. For example approximately equal estimates of $\sigma_{s}^{2}$ are obtained when $p$ is large or when $u_{i}=v_{i}$ and $p$ is small $(5<p<10)$. On the other hand when $p$ is small and $u_{i} \neq v_{i} \sigma_{s}^{2}$ from method 2 has the largest value while estimates from methods 3 and 4 have the smallest value. In general, however, $\sigma_{s}^{2}(\operatorname{method} 1)$ and $\sigma_{s}^{2}(\operatorname{method} 2)$ are expected to be marginally larger than $\sigma_{s}^{2}(\operatorname{method} 3)$ and $\sigma_{s}^{2}(\operatorname{method} 4)$ when $u_{i}=v_{i}$. These differences increase when $u_{i} \neq v_{i}$ but within each pair $\sigma_{s}^{2}(\operatorname{method} 2)>\sigma_{s}^{2}(\operatorname{method} 1)$ and $\sigma_{s}^{2}(\operatorname{method} 2) \simeq \sigma_{s}^{2}(\operatorname{method} 4)$ for all situations.

In interpreting the experimental results in table 5 it must be borne in mind that the differences between the $20 \times 20$ and $5 \times 5$ diallels and among the four methods of analysis are not subjected to the normal sampling errors. Within the $20 \times 20$ and $5 \times 5$ diallels the four methods are using the same data although the $5 \times 5$ diallels use only about a quarter of the data of the $20 \times 20$ diallel. As a result differences attributable to the four methods of analysis within the $20 \times 20$ or the $5 \times 5$ diallels are subject to very small sampling errors, hence small differences are real; and, while the sampling errors for differences between the $20 \times 20$ and $5 \times 5$ diallels will be larger, they will still be smaller than normal.

In general our experimental results (table 5) support the conclusions based upon theoretical expectations. For example, both for flowering time and final height estimates of $\sigma_{g}^{2}$ differ less when they are obtained from a $20 \times 20$ than from a $5 \times 5$ diallel (table 5 ). Thus while no systematic sequencing of the $\sigma_{g}^{2}$ estimates is possible when $p=20$, the expected trend is apparent when $p=5$, that is, for flowering time

$$
\sigma_{g}^{2}(\operatorname{method} 2)>\sigma_{g}^{2}(\operatorname{method} 1)>\sigma_{g}^{2}(\operatorname{method} 3)>\sigma_{g}^{2}(\operatorname{method} 4)
$$

and for final height

$$
\sigma_{g}^{2}(\operatorname{method} 2)<\sigma_{g}^{2}(\operatorname{method} 1)<\sigma_{g}^{2}(\operatorname{method} 3)<\sigma_{g}^{2}(\operatorname{method} 4) .
$$

Also, as expected, the estimates of $\sigma_{g}^{2}$ are relatively larger for both methods 1 and 2 when $p=5$ but smaller when $p=20$ for both characters. The same pattern, however, holds for methods 3 and 4 in respect of final height only, the reverse being true for flowering time.

Estimates of $\sigma_{s}^{2}$ also conform to our theoretical expectations but only when the comparisons are restricted to those between methods 1 and 3 and methods 2 and 4 . When $p=20 \sigma_{s}^{2}$ takes smaller values for methods 3 and 4 than for methods 1 and 2. These differences, as expected, are increased when $p$ is reduced to 5 . Furthermore, for both characters $\sigma_{s}^{2}$ increases in value when estimated from methods 1 and 2 . The estimates from methods 3 and 4 however, as expected, show no distinct pattern.

A marked feature of these analyses is that the estimates of $\sigma_{s}^{2}(\operatorname{method} 2)$ and $\sigma_{s}^{2}(\operatorname{method} 4)$ are always nearly twice those of $\sigma_{s}^{2}(\operatorname{method} 1)$ and $\sigma_{s}^{2}(\operatorname{method} 3)$ which is contrary to the theoretical expectation that they should be approximately equal (when $p=20$ ). However, $\sigma_{s}^{2}$ represents sca 
effects for methods 2 and 4 only when differences between reciprocal crosses and plot errors are non-significant. While these effects can be allowed for in the design of the analysis for methods 1 and 3, this is not possible for methods 2 and 4 especially when both reciprocal differences and plot errors are confounded as they are in the present experiment. Estimates of $\sigma_{s}^{2}$ however are reduced to approximately their true values when they are corrected by subtracting $\sigma_{\text {recips }}^{2}$ (see table 5 ).

\section{Discussion}

Table 1 shows that the genetical expectations of $\sigma_{g}^{2}$ and $\sigma_{s}^{2}$ differ for methods 1 to 4 . For $\sigma_{g}^{2}$ these differences are confined to the relative contributions made by the four constituent components while these constituent components themselves remain unchanged as $\sum u_{i} v_{i} d_{i}^{2}, \sum u_{i} v_{i} h_{i}^{2}$, $\sum u_{i}^{2} v_{i}^{2} h_{i}^{2}$ and $\sum u_{i} v_{i}\left(u_{i}-v_{i}\right) d_{i} h_{i}$, respectively. For $\sigma_{s}^{2}$, on the other hand, the differences are more complex involving the number of parents $p$, the gene frequencies $u_{i}$ and $v_{i}$ and the dominance effects $\sum h_{i}$ in ways that are not readily reducible to functions of a single component, $\sum u_{i}^{2} v_{i}^{2} h_{i}^{2}$. These differences, however, merely reflect the unique experimental situation presented by each method.

The genetical expectations of $\sigma_{g}^{2}$ and $\sigma_{s}^{2}$ for method 1 are identical with the general definitions of additive and dominance components of variation in a randomly mating population. Method 1 should therefore always provide consistent estimates of $\frac{1}{4} D_{R}$ and $\frac{1}{4} H_{R}$. This is not true, however, of methods 2, 3 and 4 . They will give close approximations of $\frac{1}{4} D_{R}$ and $\frac{1}{4} H_{R}$ only if they are estimated from diallels involving at least 20 parents. They are unlikely to do so, however, if the involvement of a large number of parents is accompanied by the use of a partial design for reducing the total number of families in the diallel.

The relationships between $\sigma_{g}^{2}$ and $\sigma_{s}^{2}$ and $D_{R}$ and $H_{R}$ are conditional upon the assumptions in section 2 being met. Methods 1 and 3 provide tests for one of these assumptions, no differences between reciprocal crosses, and an experimental design could be adopted for all of the methods that would allow for the failure of another assumption, no genotype $x$ microenvironment interactions. None of the methods, however, provide tests for the assumptions of no non-allelic interaction and linkage equilibrium. Nevertheless the data of methods 1 and 2 if analysed by the alternative method of Hayman (1954) and Jinks (1954) provide a test for these two assumptions. Furthermore, if the assumptions are met their analysis partitions the statistically defined additive and dominance components, $D_{R}$ and $H_{R}$, into gene action defined components which provide estimates of gene frequencies and of the dominance ratio.

It has often been argued (Gilbert, 1958; Kempthorne, 1976; Hinkelmann, 1976; Bulmer, 1980; Mayo, 1980) that the assumptions that must be satisfied for this partitioning to yield interpretable estimates of the genetical components are too stringent and that a genetically uninformative but relatively assumptionless analysis such as that of Griffing is, therefore, to be preferred. This argument on the one hand ignores the provision of tests of the additional assumptions made by Jinks and Hayman, and on the other hand the regularity with which users of the Griffing's analysis attempt to extend the interpretation beyond the narrow limits it imposes. For 
example, the equation of general combining ability with additive gene action and of specific combining ability with dominance makes implicit assumptions about gene action and interaction, and allele frequency and distribution that go beyond even those of the Jinks and Hayman analysis without providing justification for any of them. If, however, the primary purpose of an investigation is to measure the genetical components of variation and to test the assumptions on which the estimates are based, the diallel should not be the preferred design. The triple test cross (Kearsey and Jinks, 1968) in one or more of its many forms (Jinks, Perkins and Breese, 1969; Pooni, Jinks and Jayasekara, 1978; Pooni, Jinks and Pooni, 1980) will always be more appropriate. Indeed, the kind of information that the breeders of many crops should be seeking to guide their breeding policy can be obtained from little more than a simple analysis of random $F_{3}$ families (Jinks and Pooni, 1980; Pooni and Jinks, 1981; Jinks 1983).

Acknowledgements. Professor R. K. Singh was supported by a Royal Society Commonwealth Bursary.

\section{REFERENCES}

BREESE, E. L. 1955. Continuous variation in higher plants. Ph.D. thesis. University of Birmingham, U.K.

BULMER, M. G. 1980. The mathematical theory of quantitative genetics. Oxford University Press, Oxford, U.K.

GILBERT, N. E. 1958. Diallel cross in plant breeding. Heredity, 12, 477-492.

GRIFFING, B. 1956. Concept of general and specific combining ability in relation to diallel crossing systems. Aust. J. Biol. Sci., 9, 463-493.

HAYMAN, B. I. 1954a. The analysis of variance of diallel tables. Biometrics, 10, 235-244.

HAYMAN, B. I. 1954 b. The theory and analysis of diallel crosses. Genetics, 39, 789-809.

HINKELMANN, K. 1976. Diallel and multicross designs: what do they achieve? In Pollak, E., Kempthorne, O. and Bailey, T. B. (eds.), Proc. Int. Conf. Quant. Genet., Iowa Univ. Press, Ames, Iowa, pp. 659-676.

JINKS, J. L. 1954. The analysis of continuous variation in a diallel cross of Nicotiana rustica. Genetics, 39, 767-788.

JINKS, J. L. 1983. Biometrical genetics of heterosis, in Frankel, R. (ed.), Heterosis, Monographs on Theoretical and Applied Genetics, 6, Springer-Verlag, Berlin, pp. 1-40.

JINKS, J. L. AND PERKINS, J. M. 1970. A general method for the detection of additive, dominance and epistatic components of variation. 3. $\mathrm{F}_{2}$ and backcross populations. Heredity, 25, 419-429.

JINKS, J. L. AND POONI, H. S. 1980. Comparing predictions of mean performance and environmental sensitivity of recombinant inbred lines based upon $\mathrm{F}_{3}$ and triple test cross families. Heredity, 45, 305-312.

JINKS, J. L., PERKINS, J. M. AND BREESE, E. L. 1969. A general method for the detection of additive, dominance and epistatic components of variation. 2. Application of inbred lines. Heredity, 24, 45-57.

KEARSEY, M. J. AND JINKS, J. L. 1968. A general method of detecting additive, dominance and epistatic variation for metrical traits. 1. Theory. Heredity, 23, 403-409.

KEMPTHORNE, O. 1976. Status of quantitative genetic theory. In Pollak, E., Kempthorne, O. and Bailey, T. B. (eds.), Proc. Int. Conf. Quant. Genet., Iowa Univ. Press, Ames, Iowa, pp. 719-760.

MATHER, K. AND JiNKS, J. L. 1982. Biometrical Genetics, 3rd Edn. Chapman and Hall, London.

MATHER, K. AND VINES, A. 1952. The inheritance of height and flowering time in a cross of Nicotiana rustica. In Reeve, E. C. R. and Waddington, C. N. (eds.), Quantitative Inheritance. HMSO., London, pp. 49-80.

MAYO, O. 1980. The Theory of Plant Breeding. Clarendon Press, Oxford.

PERKINS, J. M. AND JINKS, J. L. 1970. Detection and estimation of genotype environmental, linkage and epistatic components of variation for a metrical trait. Heredity, 25, 157-177. 
POONI, H. S. AND JINKS, J. L. 1981. Sources of predictions and their reliability in predicting the properties of recombinant inbred lines which can be obtained from a cross by single seed descent. Fourth International Barley Genetics Symposia. Edinburgh, Scot land, 73-78.

POONI, H. S., JINKS, J. L. AND JAYASEKARA, N. E. M. 1978. An investigation of gene action and genotype $X$ environment interactions in two crosses of Nicotiana rustica by triple test cross and inbred line analysis. Heredity, 41, 83-92.

POONI, H. S., JINKS, J. L. AND POONI, G. S. 1980. A general method for the detection and estimation of additive, dominance and epistatic variation for metrical traits. 4. Triple test cross analysis for normal families and their selfs. Heredity, 44, 177-192. 